OPEN ACCESS

Edited by:

Karin Loser,

University of Münster, Germany

Reviewed by:

Theresa T. Lu,

Hospital for Special Surgery,

United States

Eva Reali,

Istituto Ortopedico

Galeazzi (IRCCS), Italy

*Correspondence:

Miriam Wittmann

m.wittmann@leeds.ac.uk

† Joint senior authors

Specialty section:

This article was submitted to Autoimmune and Autoinflammatory

Disorders,

a section of the journal

Frontiers in Immunology

Received: 04 June 2019

Accepted: 30 July 2019

Published: 21 August 2019

Citation:

Berekméri A, Tiganescu A, Alase AA, Vital E, Stacey $M$ and Wittmann $M$ (2019) Non-invasive Approaches for the Diagnosis of Autoimmune/Autoinflammatory Skin Diseases - A Focus on Psoriasis and Lupus erythematosus.

Front. Immunol. 10:1931. doi: 10.3389/fimmu.2019.01931

\section{Non-invasive Approaches for the Diagnosis of Autoimmune/Autoinflammatory Skin Diseases-A Focus on Psoriasis and Lupus erythematosus}

\author{
Anna Berekméri ${ }^{1,2}$, Ana Tiganescu ${ }^{3}$, Adewonuola A. Alase ${ }^{1}$, Edward Vital ${ }^{1,2}$, \\ Martin Stacey ${ }^{4 \dagger}$ and Miriam Wittmann ${ }^{1,2 * t}$ \\ ${ }^{1}$ Faculty of Medicine and Health, Leeds Institute of Rheumatic and Musculoskeletal Medicine, University of Leeds, Leeds, \\ United Kingdom, ${ }^{2}$ Leeds Biomedical Research Centre, National Institute for Health Research, Leeds Teaching Hospitals, \\ Leeds, United Kingdom, ${ }^{3}$ Faculty of Medicine and Health, Leeds Institute of Cardiovascular and Metabolic Medicine, \\ University of Leeds, Leeds, United Kingdom, ${ }^{4}$ Faculty of Biological Sciences, School of Molecular and Cellular Biology, \\ University of Leeds, Leeds, United Kingdom
}

The traditional diagnostic gold standard for inflammatory skin lesions of unclear etiology is dermato-histopathology. As this approach requires an invasive skin biopsy, biopsy processing and analysis by specialized histologists, it is a resource intensive approach requiring trained healthcare professionals. In many health care settings access to this diagnostic approach can be difficult and outside emergency cases will usually take several weeks. This scenario leads to delayed or inappropriate treatment given to patients. With dramatically increased sensitivity of a range of analysis systems including mass spectrometry, high sensitivity, multiplex ELISA based systems and PCR approaches we are now able to "measure" samples with unprecedented sensitivity and accuracy. Other important developments include the long-term monitoring of parameters using microneedle approaches and the improvement in imaging systems such as optical coherence tomography. In this review we will focus on recent achievements regarding measurements from non-invasive sampling, in particular from plucked hair and skin tape-strips which seem well suited for the diagnosis of lupus erythematosus and psoriatic inflammation, respectively. While these approaches will not replace clinical observation - they can contribute to improved subgroup diagnosis, stratified therapeutic approaches and have great potential for providing molecular and mechanistic insight in to inflammatory skin diseases.

\section{Keywords: lupus, psoriasis, skin inflammation, tape stripping, hair follicle}

\section{INTRODUCTION}

Traditionally, the diagnosis of autoimmune and inflammatory skin diseases relies on the visual assessment by experienced dermatologists as well as dermato-histopathology. Descriptive diagnosis of skin biopsies is normally based on conventional histological staining but may also include direct immunofluorescence for the detection of antibody and complement deposits. Depending on the underlying disease, blood results in particular 
regarding circulating auto-antibodies directed against structural epidermal components (pemphigus, pemphigoid) or antinuclear antibodies can give certainty regarding the underlying disease. However, as blood focused diagnostics can often be negative for cutaneous disease manifesting, key information must often be derived from analysis of skin tissue itself.

So why are changes or additions to the established diagnostic approach for inflammatory skin disease required? There are a number of reasons. Firstly, due to the non-systemic nature of many skin diseases, reliable serum biomarkers may simply be non-existent or unreliable. Secondly, the use of skin biopsies as a diagnostic tool is an invasive procedure and not always readily available in many health systems or local situations. Skin biopsies require specialized, trained health care professionals, laboratory and histology staff (dermatohistopathologists) and the time to perform biopsies in addition to the wait for result reporting, can in clinical reality often be weeks. Furthermore, as many primary health care settings lack access to specialist dermatology care, approaches suitable for general practitioners (GP) would be very welcome to support diagnostic pathways.

Apart from costs, time and staff availability, an important issue comes from the recognized need and ambition to move forward in the field of stratified medicine (also referred to as personalized medicine, precision medicine). This approach aims to recognize sub-types of diseases outside the traditional morphology based categories, allowing optimized treatment choices and thus preventing the current "trial and error" approach to identify which treatment actually works best for which patient. For this to become a reality for a wide range of patients, researchers, and clinicians need to start thinking of alternatives to conventional approaches and embrace new molecular analysis tools, parameters not traditionally included in dermatology diagnosis, and easy, non-invasive approaches. Ideally, these approaches would not require highly-trained specialists to perform and analyse results, results would be available within the first presentation of the patient ("point-ofcare" diagnostic) and would allow repeated diagnostic assessment over time.

While confirming the diagnosis of cutaneous lupus erythematosus (LE) can be challenging due to the wide variety of possible lesion morphologies, the diagnosis of psoriasis is usually directed by pathognomonic clinical presentation. So why is there a need to additional approaches regarding psoriatic inflammation? Diagnostic challenges occur for lesions which do not fall into the typical plaque type psoriasis or display minimal pathology; however, they are important to diagnose due to the existence of co-morbidities such as psoriatic arthritis and cardiovascular disease. Lesions in certain anatomical locations such as palmoplantar, retro-auricular, outer ear canal and scalp can also be challenging for both GP and trained dermatologists, and in particular skin fold lesions can often be misdiagnosed as fungal infection and treated without success with anti-fungals.

In this review we endeavor to give an overview of existing non-invasive techniques and highlight major recent advances demonstrating their potential as next generation diagnostics and as powerful tools to provide cellular and molecular insights in to inflammatory skin diseases.

\section{IMAGING}

Recent developments in imaging and imagining analysis techniques have added to our ability to assess real time changes in the skin. The most widely used imaging technique in standard care dermatology for suspicious and/or pigmented lesions is dermatoscopy. Dermatoscopy standards are developed by the international dermatoscopy society (dermoscopy-ids.org) and the approach has also been successfully used to support diagnosis of inflammatory skin conditions [for review: (13)]. Dermatoscopy needs training, although machine learning based analysis tools are successfully being developed in particular for cancerous lesions, and is usually performed in dermatology settings.

While this review does not specifically focus on imaging techniques, the following innovative approaches have to be mentioned, although they do require significant financial investments. A recent development, not yet introduced into clinical settings is Raster Scanning Optoacoustic Mesoscopy (RSOM) (4). This technique also termend photoacoustic mesoscopy is based on ultra-broadband $(10-180 \mathrm{MHz})$ detection, achieves tissue resolution of $4 \mu \mathrm{m}$ axially and $20 \mu \mathrm{m}$ laterally and importantly can visualize vascular patterns in dermal skin compartments. A number of studies have collected images from human skin including eczema, psoriasis and nail fold changes in scleroderma capillaries $(4,5)$. This imaging approach can distinguish between intra- and subepidermal morphology features typical for eczema or psoriasis lesions (5).

By contrast, optical coherence tomography (OCT), which can deliver similar morphology information [detailed comparison of OCT vs. RSOM is given in (4)], has been used in a wide range of skin lesions, in particular in neoplastic ones to assess invasiveness and depth of the tumor. OCT uses light to capture sub-micrometer resolution and creates threedimensional images from upper skin layers. The method is based on low-coherence interferometry employing near-infrared light. The use of relatively long wavelength light allows it to penetrate 1-2 mm into the tissue. This method generates detailed 3D data on skin surface roughness, tissue density, and vascular network in addition to non-invasive measurement of architectural features such as epidermal thickness. This technology is already being utilized as a biomarker for scleroderma and systemic sclerosis (6-8), preclinical diagnosis of palmar hyperkeratosis (9) and to evaluate wound re-epithelialization (10).

In psoriasis, OCT can detect all common psoriasis nail changes including leukonychia/white spots, pitting/localized surface irregularities, diffuse surface waving, onycholysis, and subungual hyperkeratosis (11). Studies evaluating psoriatic plaque vascular morphology are also beginning to surface, although are currently limited by low cohort numbers $(12,13)$.

In cutaneous LE, OCT has been shown to correlate with histological features of disease including hyperkeratosis, epidermal atrophy, and edema (14). More recently available higher resolution OCT has also been found to be of value for the diagnosis of autoimmune blistering skin diseases. However, to date-this technique is considered auxiliary to skin biopsies in this disease group $(15,16)$ and larger trials are not available yet. 
Unfortunately, at present, costly hardware, expertise and time required to analyzed skin lesions is likely to limit the use of OCT to the research setting and specialist clinics.

Microcirculatory abnormalities are found in many inflammatory skin diseases. High Resolution Laser Doppler imaging (LDI) is a single-probe, non-invasive imaging method that can quantify total local microcirculatory blood perfusion, including capillaries, arterioles, venules, and shunting vessels. Similarly to ultrasound, it is based on the Doppler effect. Briefly, when low-level light is directed onto the skin, a fraction of this light penetrates the skin and interacts with both the static tissue and the moving red blood cells (RBCs). The light that is reflected from this static tissue remains unchanged in wavelength. The light that is scattered from the moving RBCs undergoes a change in wavelength. This backscattered light is then collected by the photodetector of LDI system to provide a signal or reading that is proportional to the speed and density of the moving RBCs (17). Alteration in peripheral blood flow (as measured by LDI) has been shown to correlate with inflammation in skin psoriasis (18). More recently, our group showed that in cutaneous LE, LDI showed better correlation with histology than clinical assessment using the local Cutaneous LE Disease Area and Severity Index (CLASI) or a physician's visual analog scale (19).

\section{FUNCTIONAL SKIN TESTING}

\section{Trans-Epidermal Water Loss}

Trans-epidermal water loss (TEWL) is a validated measure of skin epidermal permeability barrier function, measured with a non-invasive Tewameter ${ }^{\circledR}$ probe $(20,21)$. Evaporation of water from the skin occurs as part of normal skin metabolism. As barrier function is disrupted, water loss increases. TEWL measures the density gradient of the water evaporation from the skin, expressed as evaporation rate $\left(\mathrm{g} / \mathrm{h} / \mathrm{m}^{2}\right)$. In addition to resting TEWL, epidermal function can be assessed by measuring TEWL recovery over time following barrier disruption by repeated tape stripping (20).

Although atopic eczema is best recognized for its barrier defects clinical and molecular evidence suggest that barrier defects play a role in psoriatic disease pathogenesis (22-25). Further, experimental skin barrier disruption leads to several psoriasis-like features including epidermal hyperproliferation, production of pro-inflammatory cytokines, increased inflammatory infiltrate, elevated vascular endothelial growth factor and consequently, increased vascularization (26-29). Conversely, glucocorticoid/corticosteroid therapy reverses many of these features to restore normal barrier function $(23,30)$. Glucocorticoids also help to maintain the barrier function by directly promoting keratinocyte differentiation pathways $(31,32)$ which result in a paradoxical improvement in barrier function (33). Interestingly, a recent transcriptomic study found a $>90 \%$ deficit in expression of the glucocorticoid-activating enzyme $11 \beta$-hydroxysteroid dehydrogenase type 1 in psoriatic plaques (34) which has also recently been shown to modulate epidermal barrier integrity (35).

Several small clinical studies have employed TEWL as a measure of treatment efficacy in psoriasis (36-40). However, the use of TEWL as a diagnostic tool has not been studied in detail due to a lack of specificity, as other skin conditions such as eczema also present with impaired epidermal barrier function $(41,42)$. A recent study by Ye et al. used TEWL to demonstrate differences in barrier recovery between stable and progressive forms of psoriasis in uninvolved skin sites (43). Further studies in larger cohorts are required to fully assess the auxiliary value of TEWL as a non-invasive diagnostic or disease activity measure in psoriasis.

TEWL is mainly examined in diseases with epidermal involvement. Thus, LE which shows inflammatory activity around the basement membrane area may not show significant changes in TEWL but this is currently unexplored.

\section{Skin Elasticity}

Skin elasticity is typically measured by a non-invasive Cutometer ${ }^{\circledR}$ probe (or similar method) which utilizes negative pressure to aspirate a small section of skin. The distance the skin travels is affected by its elastic properties and this is recorded as a series of parameters (44). This has been utilized to measure elasticity in skin disorders characterized by stiffness such as scleroderma and systemic sclerosis (45-47).

A limited number of studies have assessed changes in skin elasticity in psoriasis. Differences in total elastic and plastic deformation were found between psoriasis, dermatitis, and lichen planus patients and within patient groups compared to uninvolved sites, with psoriasis exhibiting the greatest superficial stiffness (48). This could be partly due to psoriasis exhibiting a relatively greater epidermal hyperproliferation and lower hydration than dermatitis and lichen planus $(48,49)$.

As with TEWL, changes in elasticity were also detected between uninvolved sites in patients with psoriasis and skin from healthy volunteers (50).

Skin elasticity in LE has not been studied in detail but reports indicate differential elastic fiber staining compared to lichen planopilaris which is challenging to distinguish clinically in the later stages (51), suggesting this non-invasive method merits further investigation in LE.

However, the lack of molecular information obtained through this method and variability caused by factors such as age, sunexposure, anatomical location, and ethnicity are likely to prevent this method being widely used for personalized diagnostics.

\section{EPIDERMAL SAMPLING}

\section{Non-invasive Sampling of Skin Epithelium via Tape Stripping}

Non-invasive sampling of skin epithelium via tape stripping uses adhesive tapes to "strip" the superficial layers of the skin, peeling of layers tape by tape. This method has been widely used over the last decade in research settings; however with increased sensitivity of detection methods and the given ease of sampling-this approach becomes more interesting for clinical diagnostic pathways.

Different types of tapes are available, the most widely used being the acrylic-based (D-Squame discs $-1.4 \mathrm{~cm}$ diameter, CuDerm, Dallas, TX, USA or $2.2 \mathrm{~cm}$ diameter, Monaderm, 
Monaco), and synthetic rubber-based tapes (Adhesive Research, Glen Rock, PA) but other tapes, such as Barrier (Mölnlycke, Allerod, Denmark) and cellophane tapes (Nichiban Co, Tokyo, Japan) are also utilized. Tapes are placed on the skin with gentle pressure for $2-10 \mathrm{~s}$, and then removed with a quick movement. D-squame pressure applicator (Monaderm) can be used to standardize pressure $\left(225 \mathrm{~g} / \mathrm{cm}^{2}\right)$. It has been shown that due to the stronger adhesion of corneocytes toward the stratum granulosum, the protein content of tapes decreases in parallel with the increase of tape number/depth of penetration $(52,53)$. Studies examining the depth of skin removed by tape stripping techniques indicate that in case of healthy skin, depending on anatomical location, at least 30 consecutive tapes are needed to remove the stratum corneum (SC) via D-Squame tapes (54, $55)$. We have confirmed these results by applying 50 sequential half cut D-Squame discs to a healthy skin area. Simultaneous visualization of the taped and non-taped area was performed with OCT imaging, examining the skin surface roughness and epidermal thickness (Figure 1).

Sample collection can be followed by mRNA or protein isolation from pooled tapes. The composition of buffers for protein extraction differ, however most contain Triton-X100 and protease inhibitor cocktails. Sonication steps can be applied in order to improve the yield of extracted protein.

Skin-taping requires no special preparation of the skin and no anesthetic. In the authors view the largest advantage of tape stripping is that it allows for direct sampling of the pathologically involved skin (lesional skin). In contrast to biopsies, which are not a preferred option in pediatric settings and at certain anatomical sites due to their invasiveness and potential for scar formation, tape stripping can be repeatedly performed at any anatomical site, independent of age and location (56-58).

A potential disadvantage of tape stripping lies in the difficulty of sampling standardization. Quantity and quality of sampled skin may differ not only between individuals, but also intraindividually due to differences in epidermal thickness, skin hydration and intercellular adherence (52,59-62). A study on RNA yield when sampling healthy skin at different locations demonstrated considerable inter- as well as intra-individual variations (mean RNA mass $=11 \mathrm{ng} \pm 3.6$ from the forearm, and $=91 \mathrm{ng} \pm 31$ from the back, when using 12 consecutive tapes). The authors indicated that rather than corneocytes, other associated cells (specialized keratinocytes, components of adnexal structures) are the main source of RNA recovered by tapes. In addition, a variable distribution in the normal baseline mRNA expression of pro-inflammatory IL-8 and TNF $\alpha$ was demonstrated, which could contribute to differences in disease specific anatomical predilection sites. The study highlights that despite the distinct epidermal characteristics at different sites, mRNA expression can be internally normalized to combined housekeeping gene expression levels, as they are relatively uniformly distributed (63).

Healthy skin sampling is limited to the stratum corneum (SC), however this is often not the case in pathologically involved skin, where inflammation influences not only the morphology [hyperproliferative epidermis with thickened SC in psoriasis vs. reduced SC thickness with increased corneocyte cohesion in acute eczema compared to healthy and non-lesional skin (64)], but also the cellular composition within the epidermis, barrier defects at the level of tight junctions and the basement membrane, thus allowing "leakiness" of serum components into the epidermal compartment. Therefore, the authors believe, that the term "stratum corneum sampling/harvesting" should be avoided when referring to tape stripping in diseased skin, as one cannot be certain which layers of the epidermis are collected. Moreover, additional variations can result from different sampling techniques (e.g., applied pressure, duration, the dynamic of tape removal, precise reapplication at the same site) $(61,65,66)$.

Studies focusing on transcriptomic profiling of lesional and non-lesional skin material obtained by non-invasive tape stripping are limited in number. In an early study Morhenn et al. used 20 subsequent acrylic based tapes describing distinct RNA cytokine profiles in allergic and irritant contact dermatitis using ribonuclease protection assay (67). Follow up work by Wong et al. demonstrated that the application of four rubber based tapes is sufficient to obtain adequate amount of RNA, suitable for RT-PCR and amplification for microarray analysis. However, the yield of RNA from healthy skin is low compared to inflamed skin (68). To date, only one study focusing on the "taped" mRNA profile in psoriasis showed an upregulation of TNF $\alpha$, IFN $\gamma$, KRT16, CD2, IL-23A, IL-12B, and VEGF in psoriatic lesions (69). Interestingly, this study found stronger expression of five of these mRNA levels in tape stripping material compared to punch biopsy material from adjacent sites. This highlights that although tape-striping does not sample the deeper layers of the skin, it may have an advantage in detecting epithelial diagnostic biomarkers in diseases with epidermal involvement.

However, overall there are noteworthy limitations for the use of skin tape-strip sampling for transcriptomic analysis as the quantity and quality of RNA obtained is suboptimal. This is due to the skin surface being particularly rich in RNAases and due to the fact that RNA degradation is a natural process of skin differentiation as cells mature into corneocytes. This makes the method prone to false negative results. A recent study by Dyjack et al. (70) reported an $\sim 40 \%$ failure rate in RNA isolation from non-lesional atopic dermatitis (AD) tape samples, compared to the $86 \%$ isolation success rate from lesional AD skin. Of interest, transcriptome (RNAseq)-proteome (LC-MS/MS) correlation based on full thickness skin biopsy material from lesional and non-lesional psoriatic skin demonstrated an only modest correlation (71). A clear advantage of focusing on protein detection in diagnostic approaches is their stability and the ease to measure their concentration in a timely manner.

Recent evidence suggests that protein sampling of the epidermis via tape stripping is a surprisingly efficient method to detect and study a range of mediators, from structural proteins to antimicrobial peptides, chemokines, and cytokines contributing to disease pathomechanisms, using traditional ELISA, western blot and Multiplex bead-based technologies where available. Furthermore, studies analyzing protein extracts from tape stripping with highly sensitive mass spectrometry (MS) techniques are emerging as an unbiased approach to examine disease entities not only from the perspective of 


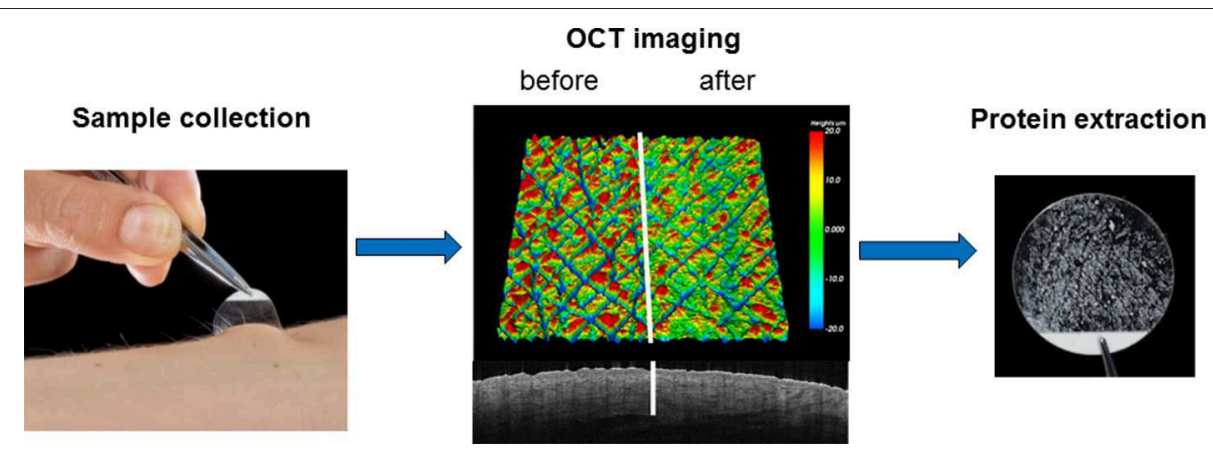

FIGURE 1 | Imaging of a $4 \mathrm{~mm}$ volar skin surface area of a healthy forearm with optical coherence tomography (OCT) after application of 50 tape stripes on the right side of the area reveals smoothening of the skin roughness. OCT imaging confirms that sampling of healthy skin remains at the level of the cornified layer and doesn't penetrate deeper than the uppermost layer of the epidermis.

disease subtype diagnosis, but importantly the detection of differentially expressed proteins can also provide potential mechanistic insight into the initiation and maintenance of these inflammatory diseases.

One of the most comprehensive tape stripping studies focusing on healthy vs. psoriatic skin identified 140 proteins expressed in lesional psoriatic skin by combining tape sampling and MS analysis (72). Compared to healthy, significant upregulation of 20 proteins were found, amongst them proteins playing role in keratinocyte differentiation, antimicrobial activity, cell-cell and cell-matrix interactions, protease inhibition and in signaling pathways (FABP5, fatty acid-binding protein; CALML5, calmodulin-like protein 5; NGAL, neutrophil gelatinase-associated lipocalin, elafin, S100A7 "psoriasin," $\alpha$ enolase, galectin-7 (members of the serpin family, 14-3-3-protein sigma). Zn- $\alpha-2$-glycoprotein was the only protein found to be downregulated in lesional vs. healthy samples. Although promising, many of the mediators found upregulated in psoriatic lesional tape samples compared to healthy have also been described to be also upregulated in tape harvested lesional $\mathrm{AD}$ skin, such as galectin-7, Serpin and S100 family members, FABP5 and $\alpha$-enolase (73-76). Galectin-7 expressed in the SC has been previously studied as an indicator of skin barrier disruption in eczema (77), and serpin B3 has been highlighted as a potential biomarker for atopic inflammation $(73,78)$, although serpin family members seem to play a pathophysiological role in psoriatic inflammation as well $(79,80)$.

Additionally, Mehul et al. (72) were able to quantify known pathophysiological chemokines in psoriatic tape samples, including CXCR3 ligands (CXCL10, CXCL11) which are involved in the chemotaxis of IFN $\gamma$ expressing lymphocytes) and CCL20 which acts on CCR6 ${ }^{+}$IL-17 producing leukocytes $(72,81,82)$. Tape sampling of psoriatic skin also detects strong expression of the neutrophil chemoattractants CXCL1 (GRO $\alpha)$ and CXCL8 (IL-8) $(72,83)$. This is in line with the neutrophilic infiltrate known to characterize psoriatic skin lesions $(84,85)$. Unlike in protein extracts from full thickness biopsies, CXCL1 was also detectable in non-lesional tape samples (72). The same study found low expression but detectable levels of IL-17 pathway cytokines including IL12p40 subunit which is part of both IL-12 and IL-23, IL17A, and IL17F in psoriatic lesional tape samples. According to the authors' experience, in contrast to epidermal chemokines, detection of lymphokines in tape stripped samples from lesional skin is not very reliable probably due to disease activity dependent differences in lymphocyte infiltration into the upper skin layers.

There are a number of studies focusing on atopic inflammation vs. healthy skin which identified elevated CCL17 (TARC) and TSLP in tape harvested material with correlations to disease severity $(86,87)$. However, none of the mentioned investigations directly compared lesional skin from different diseases which leaves interpretation on whether detected molecules are disease specific or just general inflammation markers open to discussion.

We have recently (88) compared tape harvested proteins expressed in psoriatic and atopic eczema inflammation with comparable lesion scores (e.g., local inflammatory intensity), non-lesional and healthy skin. The study identified increase expression of IL-36 $\gamma$, a pro-inflammatory IL-1 family member, as a surprisingly robust biomarker for psoriatic inflammation. These results are in line with previous research which showed significantly enhanced IL-36 $\gamma$ mRNA expression in psoriasis biopsy material compared to healthy skin and recognized IL$36 \gamma$ as an important cytokine in the pathogenesis of psoriatic inflammation (89-91). Other previously described markers including CCL20, CXCL1, and CXCL8, were also strongly increased in lesional psoriatic samples compared to eczema

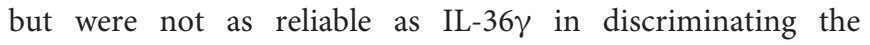
two entities.

Lesional psoriatic skin is well described to overexpress antimicrobial peptides (AMPs) in the outermost layers of the skin. Thus, non-invasive surface sampling is ideally suited study their expression in different conditions. AMPs measured via tape stripping $(92,93)$ but also "washing fluid" (94, 95) obtained from the skin surface confirmed significantly higher expression levels of hBD2 in both lesional psoriatic and eczematous skin compared to healthy controls. To date, there is no published tape stripping data regarding hBD3 expression in psoriasis, although increased secretion of hBD3 and RNase7 have been shown in non-lesional AD compared 
to healthy skin (96). Markedly elevated S100 family members (S100A7, S100A8, S100A9) expression which contribute to antimicrobial defense but are also an indicator of inflammation at epithelial surfaces, have been reported in psoriatic lesional SC (72). Identification of fecal calprotectin (formed by a heteromeric complex of two subunits, S100A8 and S100A9) is currently used as a routine non-invasive diagnostic tool to distinguish inflammatory bowel disease (IBD) from irritable bowel syndrome, to follow up disease activity and predict disease relapse (97).

All skin diseases showing epidermal inflammation present with some degree of pruritus, which is well recognized to be a complex phenomenon. Neuropeptides which can impact on release of histamine, vasoactive mediators and proinflammatory cytokines and play a role in itch. Keratinocytes are the main source of the neurotrophic nerve growth factor (NGF), a regulator of sensory nerves innervating the skin and which can induce lymphocyte activation and keratinocyte proliferation $(98,99)$. NGF has been recognized to be upregulated in both atopic and psoriatic lesional skin, and correlates positively with the severity of itch $(100,101)$. A study focusing on $\mathrm{AD}$ has shown that NGF is measurable in tape collected samples, and that its levels correlate with disease and itch severity and are found reduced following treatment (102). IL-31 also called the "pruritic cytokine"which is currently targeted by biologics approach in clinical studies-can be successfully measured in psoriatic lesional SC (72).

Metabolomics is an exciting newly emerging field. Recent data using skin and serum samples suggest that perturbations in the glycolysis and amino acid metabolic pathways may play an important role in the pathogenesis of psoriasis $(103,104)$. So far there is a lack of studies combining tape stripping with examining metabolomics data, although this could represent a valuable future approach.

\section{Other Approaches for Epidermal Sampling}

Other approaches for epidermal sampling include-as mentioned above-washing buffer approaches which seems to be particularly suitable to monitor the in vivo secretion of $\operatorname{AMP}(94,95)$.

Epidermal material can also be obtained by scraping of the skin surface with a surgical blade. For psoriasis lesions, this approach allows detection of chemokines, growth factors including VEGF and IL-1 family members (104). However, this sampling methods seems difficult to standardize.

Suction blister (105) has been successfully used in research settings to allow protein measurement of interstitial fluid from lesional skin-however this approach seems less suitable for clinical practice as it is time intense and requires special setups and training. A promising approach suitable for point of care diagnostic is the analysis of interstitial fluid by means of microneedle patches (106). This approach is being used for continuous glucose monitoring and drug bioavailability. This method has not yet been applied to inflammatory skin conditions.

\section{HAIR FOLLICLE ANALYSIS}

Hair follicles are generally referred to as an "appendage" located in the skin $(107,108)$. Hair biologists however consider the hair follicle an "end organ," with its own complex microenvironment (109). The hair producing segment of the hair follicle is constantly being renewed from a stem cell pool (110-112). The hair follicle is mainly composed of keratinocytes that make up the hair shaft as well as the inner and outer root sheaths. The hair follicle also has a specialized mesenchymal population referred to as dermal papilla (DP) (112) which play a role in regulating the activities of keratinocytes in forming a follicle and hair shaft. The hair follicle stages include anagen (active growth), catagen (degeneration of the lower follicle), telogen (quiescence), and then regeneration $(108,112)$.

The bulge region of the hair follicle is located in an area of the outer root sheath just beneath the sebaceous gland and is believed to be the reservoir for epidermal stem cells in the hair follicle (113). This region shows features of an immunologically privileged (IP) site (114). Some of the critical features indicating collapse of immune privilege, which goes along with inflammatory alopecia conditions, is the expression of $\mathrm{MCH}$ I and other related molecules, downregulation of CK15, E-cadherin and increased expression of genes associated with epithelial-mesenchymal transition, such as vimentin, fibronectin, and SLUG (115).

\section{Cutaneous Lupus}

Cutaneous lupus can present as an organ specific disease localized only to the skin or can occur as a manifestation of a systemic disease (116). The subtype of CLE that results in permanent scarring is the chronic discoid LE (CDLE) (117). CDLE lesions appear frequently on the scalp, with resultant permanent scar and irreversible hair loss $(118,119)$. The pathogenesis of CDLE involves accumulation of apoptotic materials, resulting in secondary necrosis and the activation of the interferon (IFN) pathway by nucleic materials, leading to inflammation and the recruitment of cytotoxic, IFN $\gamma$-producing $\mathrm{CD}^{+} \mathrm{T}$ cells. The recruitment of the cells to the bulge region of the hair follicles coupled with collapse of immune privilege ultimately leads to permanent hair loss and atrophic scarring (120). A key feature in LE is high expression of IFN and IFN stimulated genes (ISGs), such as myxovirus protein $\mathrm{A}(\mathrm{Mx} 1)$, IFN inducible protein 6 (IFI6), guanylate binding protein 1 (GBP-1), CXCL9, and CXCL10 (121-123). In addition to high IFN expression, IFN-induced expression of MHC I and MHC I pathway-related molecule, such as beta 2 microglobulin $(\beta 2 \mathrm{M})$ has been reported in ex vivo human scalp skin culture $(124,125)$. IFNs have antiproliferative properties on skin cells (126) and this may explain the reduced proliferation and neovascularization reported in CDLE cells and tissues, and may be major contributors to the scarring outcome (127).

The current gold standard for diagnosis of connective tissue disease manifesting at the skin organ which includes LE is dermato-immunohistopatholog and key features for LE include interface dermatitis i.e., deposition of inflammatory cells at the dermo-epidermal junction, basal cell vacuolization, keratinocytes 
TABLE 1 | Characteristics of non-invasive diagnostic approaches.

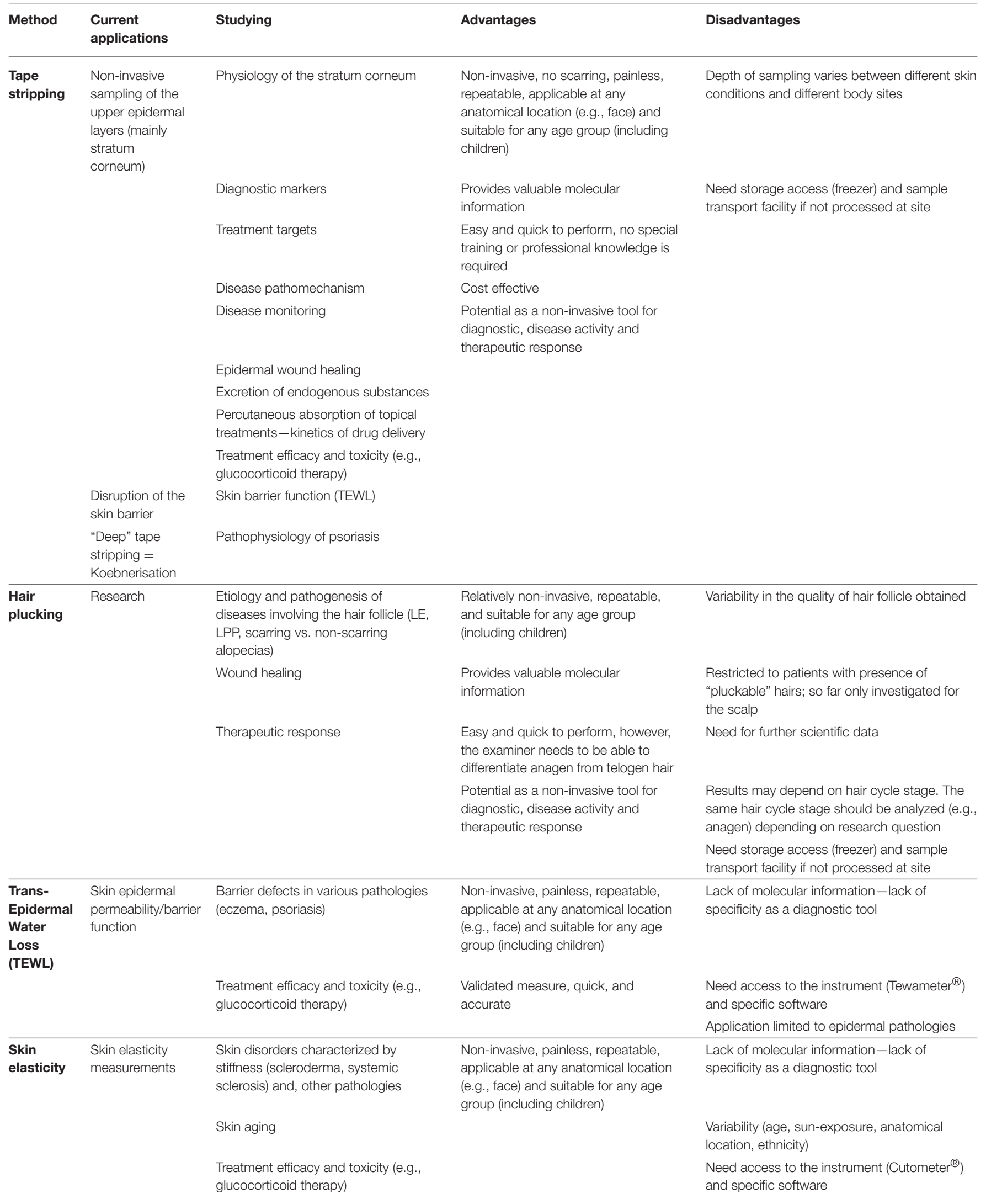


apoptosis, lymphohistiocytic infiltration around appendages and vessels, mucin deposition, basement membrane thickening, and follicular plugging $(128,129)$. An important differential diagnosis for LE of the scalp is Lichen planopilaris (LPP) which also presents as interface dermatitis in dermatohistopathology and can be difficult to distinguish in some cases. As with LE, current knowledge suggests that scarring in LPP is due to CD8 ${ }^{+}$T-cell driven attack on the epidermal stem cells of the hair follicles due to collapse of immune privilege (114).

Scalp dermatoscopy can be a useful addition to the diagnostic portfolio in dermatology settings (130). The hair follicle epithelium has been recognized as a valuable tissue for diagnostic purposes. The group of Blume-Peytavi has demonstrated the diagnostic potential of hair follicles obtained by hair plucking or cyanoacrylate surface stripping in androgenic alopecia and seborrheic dermatitis conditions (131-133).

Since the hair follicle is the main target in CDLE, we used 3-5 plucked anagen hair follicles as a non-invasive diagnostic approach (134). We found increased expression of ISGs that are known to play important role in the pathogenesis of the disease (121). Interestingly, we also found increased expression of $\beta 2 \mathrm{M}$. Both of these findings have also been made for LPP by Harries et al. (114) who used laser capture microdissection of scalp biopsy to gain hair follicle specific information (114). Of interest, regarding diagnostic difficulties for CDLE vs. LPP lesion, significant contribution of complement activation identifies LE lesions. In our analysis of plucked hair follicle derived epithelium, we found increased expression of C3 in lesional LE in comparison to non-lesional, psoriatic, and healthy hair follicles.

Of interest, despite the hair follicles not being specifically involved in type 2 diabetes, the use of hair follicles as an alternative means of diagnosing the disease has been suggested (135). This hypothesis is hinged on the prolonged shortage of oxygen supply to the hair follicles in hyperglycaemic patients thus leading to hair follicles damage, sparseness of hair, or decreased hair growth speed (136).

Based on our experience, patients are highly acceptant of hair follicle plucking (in our setup 5-10 hairs) for diagnostic or research purposes and are also happy for repeated sampling e.g., to ascertain therapeutic responses. In addition, hair follicle collection does not require specialist training.

\section{CONCLUSION}

The need to include analysis of tissue specific responses in precision medicine approaches has been recognized. Table 1 gives an overview including advantages and limitations of the main approaches discussed in this review. Dermatoscopy and functional skin testing are useful to support diagnostic processes but their use seem to be limited to specialized

\section{REFERENCES}

1. Lacarrubba F, Ardigo M, Di Stefani A, Verzi AE, Micali G. Dermatoscopy and reflectance confocal microscopy correlations in nonmelanocytic disorders. Dermatol Clin. (2018) 36:487-501. doi: 10.1016/j.det.2018. 05.015 dermatology department and training is needed for correct use and interpretation.

As highlighted in this review, novel imaging techniques have great potential to allow non-invasive diagnostic by visualizing changes in the epidermal down to the vessel compartment. Access to imaging devices such as OCT and RSOM are however limited to specialized centers due to high costs.

By contrast, epidermal sampling by tape stripping and for the scalp by hair follicle plucking do not need specific training, are easy and fast to perform, suitable for point of care approaches and can give molecular information beyond morphology changes. This could significantly help with disease subgroup identification and importantly provide a molecular understanding of the inflammatory processes behind these diseases and highlight novel targets for future therapeutics. Thus, protein biomarkers detectable with non-invasive epidermal/hair follicle sampling has the potential to direct treatment pathways, follow up disease progression and therapeutic response.

It remains to be demonstrated in well planned prospective studies which compare standard of care diagnostic with the here discussed non-invasive diagnostic approaches if suitable protein biomarker algorithm can be developed with high enough sensitivity and specificity for a range of inflammatory skin conditions to replace current biopsy approaches. Another previously discussed (137) outcome of such studies could be that approaches such as tape stripping cannot fully replace dermatohistopathology but could prove to be of significant support for treatment decision pathways either in primary care setting (e.g., inverse psoriasis vs. fungal infection; palmoplantar eczema vs. psoriasis), in secondary care dermatology (e.g., predicting response to therapy) or in other disciplines such as rheumatology (e.g., supporting the diagnosis of psoriatic arthritis). The potential of epidermal sampling to be developed into a point-of-care test for specific diagnostic problems is given by the ease of sampling. Larger trials and development of robust biomarker algorithms are needed to fully appreciate the value epidermal sampling could have in routine care settings.

\section{AUTHOR CONTRIBUTIONS}

All authors contributed to writing the manuscript. $A B$ performed the optical coherence tomography imaging shown in Figure 1.

\section{FUNDING}

This research was supported by the National Institute for Health Research (NIHR) Leeds Biomedical Research Centre. The views expressed are those of the author(s) and not necessarily those of the NHS, the NIHR, or the Department of Health.

2. Deinlein T, Richtig G, Schwab C, Scarfi F, Arzberger E, Wolf I, et al. The use of dermatoscopy in diagnosis and therapy of nonmelanocytic skin cancer. $J$ German Soc Dermatol. (2016) 14:144-51. doi: 10.1111/ddg.12903

3. Lacarrubba F, Verzi AE, Dinotta F, Scavo S, Micali G. Dermatoscopy in inflammatory and infectious skin disorders. Giorn Italiano Dermatol Venereol. (2015) 150:521-31. 
4. Hindelang B, Aguirre J, Schwarz M, Berezhnoi A, Eyerich K, Ntziachristos $\mathrm{V}$, et al. Non-invasive imaging in dermatology and the unique potential of raster-scan optoacoustic mesoscopy. J Eur Acad Dermatol Venereol. (2019) 33:1051-61. doi: 10.1111/jdv.15342

5. Aguirre J, Schwarz M, Garzorz N, Omar M, Buehler A, Eyerich K, et al. Precision assessment of label-free psoriasis biomarkers with ultra-broadband optoacoustic mesoscopy. Nat Biomed Eng. (2017) 1:0068. doi: 10.1038/s41551-017-0068

6. Abignano G, Aydin SZ, Castillo-Gallego C, Liakouli V, Woods D, Meekings A, et al. Virtual skin biopsy by optical coherence tomography: the first quantitative imaging biomarker for scleroderma. Ann Rheum Dis. (2013) 72:1845-51. doi: 10.1136/annrheumdis-2012-202682

7. Abignano G, Del Galdo F. Quantitating skin fibrosis: innovative strategies and their clinical implications. Curr Rheumatol Rep. (2014) 16:404. doi: 10.1007/s11926-013-0404-5

8. Kang T, Abignano G, Lettieri G, Wakefield RJ, Emery P, Del Galdo F. Skin imaging in systemic sclerosis. Eur J Rheumatol. (2014) 1:1116. doi: 10.5152/eurjrheumatol.2014.036

9. Abignano G, Kapadia A, Lettieri G, Goodfield M, Emery P, McGonagle D, et al. Use of optical coherence tomography for the diagnosis of preclinical lesions of circumscribed palmar hypokeratosis. Clin Exp Dermatol. (2017) 42:192-5. doi: 10.1111/ced.13027

10. Greaves NS, Benatar B, Whiteside S, Alonso-Rasgado T, Baguneid M, Bayat A. Optical coherence tomography: a reliable alternative to invasive histological assessment of acute wound healing in human skin? Brit J Dermatol. (2014) 170:840-50. doi: 10.1111/bjd.12786

11. Abignano G, Laws P, Del Galdo F, Marzo-Ortega H, McGonagle D. Three-dimensional nail imaging by optical coherence tomography: a novel biomarker of response to therapy for nail disease in psoriasis and psoriatic arthritis. Ann Rheum Dis. (2017) 76:734. doi: 10.1136/annrheumdis-2017-eular.4157

12. Deegan AJ, Talebi-Liasi F, Song SZ, Li YD, Xu JJ, Men SJ, et al. Optical coherence tomography angiography of normal skin and inflammatory dermatologic conditions. Lasers Surg Med. (2018) 50:18393. doi: $10.1002 / \mathrm{lsm} .22788$

13. Odorici G, Losi A, Ciardo S, Pellacani G, Conti A. Non-invasive evaluation of Secukinumab efficacy in severe plaque psoriasis with confocal microscopy and optical coherence tomography: a case report. Skin Res Technol. (2018) 24:160-2. doi: 10.1111/srt.12409

14. Gambichler T, Hyun J, Moussa G, Tomi NS, Boms S, Altmeyer P, et al. Optical coherence tomography of cutaneous lupus erythematosus correlates with histopathology. Lupus. (2007) 16:35-8. doi: 10.1177/0961203306074773

15. Mandel VD, Cinotti E, Benati E, Labeille B, Ciardo S, Vaschieri C, et al. Reflectance confocal microscopy and optical coherence tomography for the diagnosis of bullous pemphigoid and pemphigus and surrounding subclinical lesions. J Eur Acad Dermatol Venereol. (2018) 32:15629. doi: 10.1111/jdv.14795

16. Capocasale G, Panzarella V, Rodolico V, Di Fede O, Campisi G. In vivo optical coherence tomography imaging in a case of mucous membrane pemphigoid and a negative Nikolsky's sign. J Dermatol. (2018) 45:6035. doi: 10.1111/1346-8138.14267

17. Wardell K, Jakobsson A, Nilsson GE. Laser Doppler perfusion imaging by dynamic light scattering. IEEE Trans Biomed Eng. (1993) 40:30916. doi: $10.1109 / 10.222322$

18. Hendriks AG, Steenbergen W, Hondebrink E, van Hespen JC, van de Kerkhof PC, Seyger MM. Whole field laser Doppler imaging of the microcirculation in psoriasis and clinically unaffected skin. J Dermatol Treat. (2014) 25:18-21. doi: 10.3109/09546634.2013.777382

19. Md Yusof MY, Britton J, Hensor EM, Goodfield M, Wittmann M, Emery P, Vital EM. Laser Doppler imaging: an objective outcome measure for assessment of cutaneous lupus erythematosus. Ann Rheum Dis. (2017) 76(Suppl. 2):1019-20. doi: 10.1136/annrheumdis-2017-eular.6784

20. Grubauer G, Elias PM, Feingold KR. Transepidermal water loss: the signal for recovery of barrier structure and function. J Lipid Res. (1989) 30:323-33.

21. Alexander H, Brown S, Danby S, Flohr C. Research techniques made simple: transepidermal water loss measurement as a research tool. J Investig Dermatol. (2018) 138:2295-300.e1. doi: 10.1016/j.jid.2018. 09.001
22. Gottlieb AB, Staiano-Coico L, Cohen SR, Varghese M, Carter DM. Occlusive hydrocolloid dressings decrease keratinocyte population growth fraction and clinical scale and skin thickness in active psoriatic plaques. J Dermatol Sci. (1990) 1:93-6. doi: 10.1016/0923-1811(90)90221-X

23. Volden G, Kragballe K, Van De Kerkhof PC, Aberg K, White RJ. Remission and relapse of chronic plaque psoriasis treated once a week with clobetasol propionate occluded with a hydrocolloid dressing versus twice daily treatment with clobetasol propionate alone. J Dermatolog Treat. (2001) 12:141-4. doi: 10.1080/09546630152607862

24. Bergboer JGM, Zeeuwen PLJM, Schalkwijk J. Genetics of psoriasis: evidence for epistatic interaction between skin barrier abnormalities and immune deviation. J Investig Dermatol. (2012) 132:2320-31. doi: 10.1038/jid.2012.167

25. Friedman SJ. Management of psoriasis-vulgaris with a hydrocolloid occlusive dressing. Arch Dermatol. (1987) 123:104652. doi: 10.1001/archderm.123.8.1046

26. Proksch E, Feingold KR, Man MQ, Elias PM. Barrier function regulates epidermal DNA-synthesis. J Clin Investig. (1991) 87:1668-73. doi: 10.1172/JCI115183

27. Wood LC, Elias PM, Calhoun C, Tsai JC, Grunfeld C, Feingold KR. Barrier disruption stimulates interleukin-1 alpha expression and release from a preformed pool in murine epidermis. J Investig Dermatol. (1996) 106:397403. doi: 10.1111/1523-1747.ep12343392

28. Lin TK, Man MQ, Santiago JL, Park K, Roelandt T, Oda Y, et al. Topical antihistamines display potent anti-inflammatory activity linked in part to enhanced permeability barrier function. J Investig Dermatol. (2013) 133:46978. doi: 10.1038/jid.2012.335

29. Elias PM, Arbiser J, Brown BE, Rossiter H, Man MQ, Cerimele F, et al. Epidermal vascular endothelial growth factor production is required for permeability barrier homeostasis, dermal angiogenesis, and the development of epidermal hyperplasia - Implications for the pathogenesis of psoriasis. Am J Pathol. (2008) 173:689-99. doi: 10.2353/ajpath.2008.080088

30. Satake K, Amano T, Okamoto T. Low systemic exposure and calcemic effect of calcipotriol/betamethasone ointment in rats with imiquimodinduced psoriasis-like dermatitis. Eur J Pharmacol. (2018) 826:318. doi: 10.1016/j.ejphar.2018.02.032

31. Lee B, Vouthounis C, Stojadinovic O, Brem H, Im M, Tomic-Canic M. From an enhanceosome to a repressosome: molecular antagonism between glucocorticoids and EGF leads to inhibition of wound healing. J Mol Biol. (2005) 345:1083-97. doi: 10.1016/j.jmb.2004.11.027

32. Laurence EB, Christophers E. Selective action of hydrocortisone on postmitotic epidermal cells in vivo. J Investig Dermatol. (1976) 66:2229. doi: 10.1111/1523-1747.ep12482145

33. Lin TK, Man MQ, Santiago JL, Scharschmidt TC, Hupe M, Martin-Ezquerra $\mathrm{G}$, et al. Paradoxical benefits of psychological stress in inflammatory dermatoses models are glucocorticoid mediated. J Investig Dermatol. (2014) 134:2890-7. doi: 10.1038/jid.2014.265

34. Li BS, Tsoi LC, Swindell WR, Gudjonsson JE, Tejasvi T, Johnston A, et al. Transcriptome analysis of psoriasis in a large case-control sample: RNAseq provides insights into disease mechanisms. J Investig Dermatol. (2014) 134:1828-38. doi: 10.1038/jid.2014.28

35. Tiganescu A, Hupe M, Uchida Y, Mauro T, Elias PM, Holleran WM. Topical 11 beta-hydroxysteroid dehydrogenase type 1 inhibition corrects cutaneous features of systemic glucocorticoid excess in female mice. Endocrinology. (2018) 159:547-56. doi: 10.1210/en.2017-00607

36. Berardesca E, Vignoli GP, Farinelli N, Vignini M, Distante F, Rabbiosi G. Noninvasive evaluation of topical calcipotriol versus clobetasol in the treatment of psoriasis. Acta Derm Venereol. (1994) 74:302-4.

37. Hagemann I, Proksch E. Topical treatment by urea reduces epidermal hyperproliferation and induces differentiation in psoriasis. Acta Derm Venereol. (1996) 76:353-6.

38. Liu M, Li X, Chen XY, Xue F, Zheng J. Topical application of a linoleic acidceramide containing moisturizer exhibit therapeutic and preventive benefits for psoriasis vulgaris: a randomized controlled trial. Dermatol Ther. (2015) 28:373-82. doi: 10.1111/dth.12259

39. Rajabi-Estarabadi A, Hasanzadeh H, Taheri A, Feldman SR, Firooz A. The efficacy of short-term clobetasol lotion in the treatment of scalp psoriasis. J Dermatol Treat. (2018) 29:111-5. doi: 10.1080/09546634.2017.13 41616 
40. Darlenski R, Hristakieva E, Aydin U, Gancheva D, Gancheva T, Zheleva A, et al. Epidermal barrier and oxidative stress parameters improve during in $311 \mathrm{~nm}$ narrow band UVB phototherapy of plaque type psoriasis. J Dermatol Sci. (2018) 91:28-34. doi: 10.1016/j.jdermsci.2018.03.011

41. Man G, Elias PM, Man MQ. Therapeutic benefits of enhancing permeability barrier for atopic eczema. Dermatol Sin. (2015) 33:84-9. doi: 10.1016/j.dsi.2015.03.006

42. Elias PM, Wakefield JS. Mechanisms of abnormal lamellar body secretion and the dysfunctional skin barrier in patients with atopic dermatitis. J Allergy Clin Immun. (2014) 134:781-91.e1. doi: 10.1016/j.jaci.2014.05.048

43. Ye L, Lv CZ, Man G, Song SP, Elias PM, Man MQ. Abnormal epidermal barrier recovery in uninvolved skin supports the notion of an epidermal pathogenesis of psoriasis. J Investig Dermatol. (2014) 134:28436. doi: 10.1038/jid.2014.205

44. Neto P, Ferreira M, Bahia F, Costa P. Improvement of the methods for skin mechanical properties evaluation through correlation between different techniques and factor analysis. Skin Res Technol. (2013) 19:40516. doi: $10.1111 /$ srt. 12060

45. NikkelsTassoudji N, Henry F, PierardFranchimont C, Pierard GE. Computerized evaluation of skin stiffening in scleroderma. Eur J Clin Investig. (1996) 26:457-60. doi: 10.1046/j.1365-2362.1996.154303.x

46. Osmola-Mankowska A, Silny W, Danczak-Pazdrowska A, Polanska A, Olek-Hrab K, Sadowska-Przytocka A, et al. "Assessment of chronic sclerodermoid Graft-versus-Host Disease patients, using $20 \mathrm{MHz}$ highfrequency ultrasonography and cutometer methods". Skin Res Technol. (2013) 19:E417-22. doi: 10.1111/j.1600-0846.2012.00659.x

47. Dobrev HP. In vivo study of skin mechanical properties in patients with systemic sclerosis. J Am Acad Dermatol. (1999) 40:436-42. doi: 10.1016/S0190-9622(99)70494-9

48. Yazdanparast $T$, Yazdani $K$, Humbert $\mathrm{P}$, Khatami A, Ahmad Nasrollahi S, Hassanzadeh $\mathrm{H}$, et al. Comparison of biophysical, biomechanical and ultrasonographic properties of skin in chronic dermatitis, psoriasis and lichen planus. Med J Islam Repub Iran. (2018) 32:108. doi: 10.14196/mjiri.32.108

49. Bovenschen HJ, Seyger MM, Van de Kerkhof PC. Plaque psoriasis vs. atopic dermatitis and lichen planus: a comparison for lesional T-cell subsets, epidermal proliferation and differentiation. Br J Dermatol. (2005) 153:728. doi: 10.1111/j.1365-2133.2005.06538.x

50. Dobrev H. In vivo study of skin mechanical properties in psoriasis vulgaris. Acta Derm Venereol. (2000) 80:263-6. doi: 10.1080/000155500750012135

51. Farzaneh Asadi Kani Z, Nasiri S, Rafiei R, Younespour S. Evaluation of elastic fibers pattern with orcein staining in differential diagnosis of lichen planopilaris and discoid lupus erythematosus. Acta Med Iran. (2014) 52:2207.

52. King CS, Barton SP, Nicholls S, Marks R. The change in properties of the stratum corneum as a function of depth. Br J Dermatol. (1979) 100:16572. doi: 10.1111/j.1365-2133.1979.tb05556.x

53. Clausen M-L, Slotved HC, Krogfelt KA, Agner T. Tape stripping technique for stratum corneum protein analysis. Sci Rep. (2016) 6:19918. doi: $10.1038 /$ srep 19918

54. Pinkus H. Examination of the epidermis by the strip method of removing horny layers. I. Observations on thickness of the horny layer, and on mitotic activity after stripping. J Investig Dermatol. (1951) 16:3836. doi: 10.1038/jid.1951.45

55. Solberg J, Ulrich NH, Krustrup D, Ahlstrom MG, Thyssen JP, Menne T, et al. Skin tape stripping: which layers of the epidermis are removed? Contact Dermatitis. (2018) 80:319-21. doi: 10.1111/cod.13199

56. McAleer MA, Jakasa I, Hurault G, Sarvari P, McLean WHI, Tanaka RJ, et al. Systemic and stratum corneum biomarkers of severity in infant atopic dermatitis include markers of innate and $\mathrm{T}$ helper cell-related immunity and angiogenesis. Br J Dermatol. (2019) 180:586-96. doi: 10.1111/bjd. 17088

57. Hulshof L, Hack DP, Hasnoe QCJ, Dontje B, Jakasa I, Riethmüller C, et al. A minimally invasive tool to study immune response and skin barrier in children with atopic dermatitis. Br J Dermatol. (2019) 180:62130. doi: 10.1111/bjd.16994

58. Furue M. Useful components in the stratum corneum for assessment of atopic dermatitis. Br J Dermatol. (2019) 180:457-8. doi: 10.1111/bjd.17117
59. van der Molen RG, Spies F, van ‘t Noordende JM, Boelsma E, Mommaas AM, Koerten HK. Tape stripping of human stratum corneum yields cell layers that originate from various depths because of furrows in the skin. Archiv Dermatol Res. (1997) 289:514-8. doi: 10.1007/s004030050232

60. Black D, Del Pozo A, Lagarde JM, Gall Y. Seasonal variability in the biophysical properties of stratum corneum from different anatomical sites. Skin Res Technol. (2000) 6:70-6. doi: 10.1034/j.1600-0846.2000.006002070.x

61. Löffler H, Dreher F, Maibach HI. Stratum corneum adhesive tape stripping: influence of anatomical site, application pressure, duration and removal. $\mathrm{Br}$ J Dermatol. (2004) 151:746-52. doi: 10.1111/j.1365-2133.2004.06084.x

62. Raj N, Voegeli R, Rawlings AV, Gibbons S, Munday MR, Summers $B$, et al. Variation in stratum corneum protein content as a function of anatomical site and ethnic group. Int J Cosmet Sci. (2016) 38:22431. doi: 10.1111 /ics. 12274

63. Wong R, Tran V, Talwalker S, Benson NR. Analysis of RNA recovery and gene expression in the epidermis using non-invasive tape stripping. $J$ Dermatol Sci. (2006) 44:81-92. doi: 10.1016/j.jdermsci.2006.08.007

64. Voegeli R, Rawlings AV, Breternitz M, Doppler S, Schreier $\mathrm{T}$, Fluhr JW. Increased stratum corneum serine protease activity in acute eczematous atopic skin. $\mathrm{Br} J$ Dermatol. (2009) 161:70-7. doi: 10.1111/j.1365-2133.2009.09142.x

65. Breternitz M, Flach M, Präßler J, Elsner P, Fluhr JW. Acute barrier disruption by adhesive tapes is influenced by pressure, time and anatomical location: integrity and cohesion assessed by sequential tape stripping; a randomized, controlled study. Br J Dermatol. (2007) 156:23140. doi: 10.1111/j.1365-2133.2006.07632.x

66. Lademann J, Jacobi U, Surber C, Weigmann HJ, Fluhr JW. The tape stripping procedure - evaluation of some critical parameters. Eur J Pharmaceut Biopharmaceut. (2009) 72:317-23. doi: 10.1016/j.ejpb.2008.08.008

67. Morhenn VB, Chang E-Y, Rheins LA. A noninvasive method for quantifying and distinguishing inflammatory skin reactions. J Am Acad Dermatol. (1999) 41:687-92. doi: 10.1016/S0190-9622(99)70002-2

68. Wong R, Tran V, Morhenn V, Hung S-p, Andersen B, Ito E, et al. Use of RTPCR and DNA microarrays to characterize RNA recovered by non-invasive tape harvesting of normal and inflamed skin. J Investig Dermatol. (2004) 123:159-67. doi: 10.1111/j.0022-202X.2004.22729.x

69. Benson NR, Papenfuss J, Wong R, Motaal A, Tran V, Panko J, et al. An analysis of select pathogenic messages in lesional and non-lesional psoriatic skin using non-invasive tape harvesting. J Investig Dermatol. (2006) 126:2234-41. doi: 10.1038/sj.jid.5700412

70. Dyjack N, Goleva E, Rios C, Kim BE, Bin L, Taylor P, et al. Minimally invasive skin tape strip RNA sequencing identifies novel characteristics of the type 2-high atopic dermatitis disease endotype. J Allergy Clin Immunol. (2018) 141:1298-309. doi: 10.1016/j.jaci.2017.10.046

71. Swindell WR, Remmer HA, Sarkar MK, Xing X, Barnes DH, Wolterink $\mathrm{L}$, et al. Proteogenomic analysis of psoriasis reveals discordant and concordant changes in mRNA and protein abundance. Genome Med. (2015) 7:86. doi: 10.1186/s13073-015-0208-5

72. Mehul B, Laffet G, Seraidaris A, Russo L, Fogel P, Carlavan I, et al. Noninvasive proteome analysis of psoriatic stratum corneum reflects pathophysiological pathways and is useful for drug profiling. $\mathrm{Br}$ J Dermatol. (2017) 177:470-88. doi: 10.1111/bjd.15346

73. Broccardo CJ, Mahaffey SB, Strand M, Reisdorph NA, Leung DY. Peeling off the layers: skin taping and a novel proteomics approach to study atopic dermatitis. J Allergy Clin Immunol. (2009) 124:1113-5.e111. doi: 10.1016/j.jaci.2009.07.057

74. Sakabe J-I, Kamiya K, Yamaguchi H, Ikeya S, Suzuki T, Aoshima M, et al. Proteome analysis of stratum corneum from atopic dermatitis patients by hybrid quadrupole-orbitrap mass spectrometer. J Allergy Clin Immunol. (2014) 134:957-60.e8. doi: 10.1016/j.jaci.2014.07.054

75. Winget JM, Finlay D, Mills Kevin J, Huggins T, Bascom C, Isfort RJ, et al. Quantitative proteomic analysis of stratum corneum dysfunction in adult chronic atopic dermatitis. J Investig Dermatol. (2016) 136:17325. doi: 10.1016/j.jid.2016.03.037

76. Reisdorph N, Armstrong M, Powell R, Quinn K, Legg K, Leung D, et al. Quantitation of peptides from non-invasive skin tapings using isotope dilution and tandem mass spectrometry. J Chromatogr B. (2018) 1084:13240. doi: 10.1016/j.jchromb.2018.03.031 
77. Niiyama S, Yoshino T, Yasuda C, Yu X, Izumi R, Ishiwatari S, et al. Galectin7 in the stratum corneum: a biomarker of the skin barrier function. Int J Cosmet sci. (2016) 38:487-95. doi: 10.1111/ics.12326

78. Mitsuishi K, Nakamura T, Sakata Y, Yuyama N, Arima K, Sugita $\mathrm{Y}$, et al. The squamous cell carcinoma antigens as relevant biomarkers of atopic dermatitis. Clin Exper Allergy. (2005) 35:1327-33. doi: 10.1111/j.1365-2222.2005.02353.x

79. Takeda A, Higuchi D, Takahashi T, Ogo M, Baciu P, Goetinck $\mathrm{PF}$, et al. Overexpression of serpin squamous cell carcinoma antigens in psoriatic skin. J Investig Dermatol. (2002) 118:14754. doi: 10.1046/j.0022-202x.2001.01610.x

80. Sun Y, Sheshadri N, Zong W-X. SERPINB3 and B4: from biochemistry to biology. Sem Cell Develop Biol. (2017) 62:1707. doi: 10.1016/j.semcdb.2016.09.005

81. Nestle FO, Kaplan DH, Barker J. Psoriasis. New Engl J Med. (2009) 361:496509. doi: 10.1056/NEJMra0804595

82. Nedoszytko B, Sokołowska-Wojdyło M, Ruckemann-Dziurdzinska K, Roszkiewicz J, Nowicki RJ. Chemokines and cytokines network in the pathogenesis of the inflammatory skin diseases: atopic dermatitis, psoriasis and skin mastocytosis. Postepy Dermatol Alergol. (2014) 31:8491. doi: 10.5114/pdia.2014.40920

83. Berekmeri A, Latzko A, Alase A, Macleod T, Ainscough JS, Laws P, et al. Detection of IL-36gamma through noninvasive tape stripping reliably discriminates psoriasis from atopic eczema. J Allergy Clin Immunol. (2018) 142:988-91.e4. doi: 10.1016/j.jaci.2018.04.031

84. Gillitzer R, Ritter U, Spandau U, Goebeler M, Bröcker E-B. Differential expression of GRO- $\alpha$ and IL- 8 mRNA psoriasis: a model for neutrophil migration and accumulation in vivo. J Investig Dermatol. (1996) 107:77882. doi: 10.1111/1523-1747.ep12371803

85. De Rosa G, Mignogna C. The histopathology of psoriasis. Reumatismo. (2007) 59(Suppl. 1):46-8. doi: 10.4081/reumatismo.2007.1s.46

86. Morita E, Takahashi H, Niihara H, Dekio I, Sumikawa Y, Murakami $\mathrm{Y}$, et al. Stratum corneum TARC level is a new indicator of lesional skin inflammation in atopic dermatitis. Allergy. (2010) 65:1166-72. doi: 10.1111/j.1398-9995.2010.02361.x

87. Sano Y, Masuda K, Tamagawa-Mineoka R, Matsunaka H, Murakami Y, Yamashita R, et al. Thymic stromal lymphopoietin expression is increased in the horny layer of patients with atopic dermatitis. Clin Exp Immunol. (2013) 171:330-7. doi: 10.1111/cei.12021

88. D'Erme AM, Wilsmann-Theis D, Wagenpfeil J, Holzel M, Ferring-Schmitt S, Sternberg S, et al. IL-36gamma (IL-1F9) is a biomarker for psoriasis skin lesions. J Investig Dermatol. (2015) 135:1025-32. doi: 10.1038/jid.2014.532

89. Muhr P, Zeitvogel J, Heitland I, Werfel T, Wittmann M. Expression of interleukin (IL)-1 family members upon stimulation with IL-17 differs in keratinocytes derived from patients with psoriasis and healthy donors. Br J Dermatol. (2011) 165:189-93. doi: 10.1111/j.1365-2133.2011. 10302.x

90. Liang Y, Sarkar MK, Tsoi LC, Gudjonsson JE. Psoriasis: a mixed autoimmune and autoinflammatory disease. Curr Opin Immunol. (2017) 49:1-8. doi: 10.1016/j.coi.2017.07.007

91. Buhl A-L, Wenzel J. Interleukin-36 in infectious and inflammatory skin diseases. Front Immunol. (2019) 10:1162. doi: 10.3389/fimmu.2019.01162

92. Asano S, Ichikawa Y, Kumagai T, Kawashima M, Imokawa G. Microanalysis of an antimicrobial peptide, $\beta$-defensin-2, in the stratum corneum from patients with atopic dermatitis. Br J Dermatol. (2008) 159:97104. doi: 10.1111/j.1365-2133.2008.08613.x

93. Clausen ML, Jungersted JM, Andersen PS, Slotved HC, Krogfelt KA, Agner T. Human beta-defensin-2 as a marker for disease severity and skin barrier properties in atopic dermatitis. Br J Dermatol. (2013) 169:58793. doi: 10.1111/bjd.12419

94. Glaser R, Meyer-Hoffert U, Harder J, Cordes J, Wittersheim M, Kobliakova J, et al. The antimicrobial protein psoriasin (S100A7) is upregulated in atopic dermatitis and after experimental skin barrier disruption. J Investig Dermatol. (2009) 129:641-9. doi: 10.1038/jid.2008.268

95. Wittersheim M, Cordes J, Meyer-Hoffert U, Harder J, Hedderich J, Glaser R. Differential expression and in vivo secretion of the antimicrobial peptides psoriasin (S100A7), RNase 7, human beta-defensin-2 and-3 in healthy human skin. Exp Dermatol. (2013) 22:364-6. doi: 10.1111/exd.12133
96. Clausen M-L, Slotved HC, Krogfelt KA, Agner T. Measurements of AMPs in stratum corneum of atopic dermatitis and healthy skin-tape stripping technique. Sci Rep. (2018) 8:1666. doi: 10.1038/s41598-018-20204-8

97. Laserna-Mendieta Emilio J, Lucendo Alfredo J. Faecal calprotectin in inflammatory bowel diseases: a review focused on metaanalyses and routine usage limitations. Clin Chem Lab Med. (2019) 57:1295-1307. doi: 10.1515/cclm-2018-1063

98. Raychaudhuri SP, Jiang WY, Farber EM. Psoriatic keratinocytes express high levels of nerve growth factor. Acta Dermatovenereol Stockholm. (1998) 78:84-6. doi: 10.1080/0001555984 33368

99. Pincelli C. Nerve growth factor and keratinocytes: a role in psoriasis. Eur J Dermatol. (2000) 10:85-90.

100. Nakamura M, Toyoda M, Morohashi M. Pruritogenic mediators in psoriasis vulgaris: comparative evaluation of itch-associated cutaneous factors. $\mathrm{Br} \mathrm{J}$ Dermatol. (2003) 149:718-30. doi: 10.1046/j.1365-2133.2003.05586.x

101. Dou Y-C, Hagströmer L, Emtestam L, Johansson O. Increased nerve growth factor and its receptors in atopic dermatitis: an immunohistochemical study. Archiv Dermatol Res. (2006) 298:31-7. doi: 10.1007/s00403-006-0657-1

102. Yamaguchi J, Aihara M, Kobayashi Y, Kambara T, Ikezawa Z. Quantitative analysis of nerve growth factor (NGF) in the atopic dermatitis and psoriasis horny layer and effect of treatment on NGF in atopic dermatitis. J Dermatol Sci. (2009) 53:48-54. doi: 10.1016/j.jdermsci.2008.08.011

103. Yan D, Afifi L, Jeon C, Trivedi M, Chang HW, Lee K, et al. The metabolomics of psoriatic disease. Psoriasis. (2017) 7:1-15. doi: 10.2147/PTT.S118348

104. Kang H, Li X, Zhou Q, Quan C, Xue F, Zheng J, et al. Exploration of candidate biomarkers for human psoriasis based on gas chromatographymass spectrometry serum metabolomics. Br J Dermatol. (2017) 176:71322. doi: 10.1111/bjd.15008

105. Svoboda $M$, Hlobilová $M$, Marešová $M$, Sochorová $M$, Kováčik A, Vávrová $\mathrm{K}$, et al. Comparison of suction blistering and tape stripping for analysis of epidermal genes, proteins and lipids. Archiv Dermatol Res. (2017) 309:75765. doi: 10.1007/s00403-017-1776-6

106. Kolluru C, Williams M, Yeh JS, Noel RK, Knaack J, Prausnitz MR. Monitoring drug pharmacokinetics and immunologic biomarkers in dermal interstitial fluid using a microneedle patch. Biomed Microdevices. (2019) 21:14. doi: 10.1007/s10544-019-0363-3

107. Hardy MH. The secret life of the hair follicle. Trends Genet. (1992) 8:5561. doi: 10.1016/0168-9525(92)90044-5

108. Legue E, Sequeira I, Nicolas JF. Hair follicle renewal: authentic morphogenesis that depends on a complex progression of stem cell lineages. Development. (2010) 137:569-77. doi: 10.1242/dev.044123

109. Rishikaysh P, Dev K, Diaz D, Qureshi WM, Filip S, Mokry J. Signaling involved in hair follicle morphogenesis and development. Int J Mol Sci. (2014) 15:1647-70. doi: 10.3390/ijms15011647

110. Cotsarelis G, Sun TT, Lavker RM. Label-retaining cells reside in the bulge area of pilosebaceous unit: implications for follicular stem cells, hair cycle, and skin carcinogenesis. Cell. (1990) 61:1329-37. doi: 10.1016/0092-8674(90)90696-C

111. Fuchs E, Horsley V. More than one way to skin. Genes Dev. (2008) 22:97685. doi: 10.1101/gad.1645908

112. Morgan BA. The dermal papilla: an instructive niche for epithelial stem and progenitor cells in development and regeneration of the hair follicle. CSH Perspect Med. (2014) 4:a015180. doi: 10.1101/cshperspect.a015180

113. Ohyama M, Terunuma A, Tock CL, Radonovich MF, Pise-Masison $\mathrm{CA}$, Hopping SB, et al. Characterization and isolation of stem cellenriched human hair follicle bulge cells. J Clin Invest. (2006) 116:24960. doi: $10.1172 /$ JCI26043

114. Harries MJ, Meyer K, Chaudhry I, J EK, Poblet E, Griffiths CE, et al. Lichen planopilaris is characterized by immune privilege collapse of the hair follicle's epithelial stem cell niche. J Pathol. (2013) 231:236-47. doi: 10.1002/path.4233

115. Imanishi H, Ansell DM, Cheret J, Harries M, Bertolini M, Sepp N, et al. Epithelial-to-mesenchymal stem cell transition in a human organ: lessons from lichen planopilaris. J Invest Dermatol. (2018) 138:5119. doi: 10.1016/j.jid.2017.09.047

116. Robinson ES, Werth VP. The role of cytokines in the pathogenesis of cutaneous lupus erythematosus. Cytokine. (2015) 73:326-34. doi: 10.1016/j.cyto.2015.01.031 
117. Gronhagen CM, Fored CM, Granath F, Nyberg F. Cutaneous lupus erythematosus and the association with systemic lupus erythematosus: a population-based cohort of 1088 patients in Sweden. Br J Dermatol. (2011) 164:1335-41. doi: 10.1111/j.1365-2133.2011.10272.x

118. Al-Refu K, Goodfield M. Hair follicle stem cells in the pathogenesis of the scarring process in cutaneous lupus erythematosus. Autoimmun Rev. (2009) 8:474-7. doi: 10.1016/j.autrev.2008.12.015

119. Chung HJ, Goldberg LJ. Histologic features of chronic cutaneous lupus erythematosus of the scalp using horizontal sectioning: emphasis on follicular findings. J Am Acad Dermatol. (2017) 77:349-55. doi: 10.1016/j.jaad.2017.02.039

120. Wenzel J, Tuting T. An IFN-associated cytotoxic cellular immune response against viral, self-, or tumor antigens is a common pathogenetic feature in "interface dermatitis". J Invest Dermatol. (2008) 128:2392402. doi: $10.1038 /$ jid.2008.96

121. Zahn S, Rehkamper C, Kummerer BM, Ferring-Schmidt S, Bieber T, Tuting $\mathrm{T}$, et al. Evidence for a pathophysiological role of keratinocyte-derived type III interferon (IFNlambda) in cutaneous lupus erythematosus. J Invest Dermatol. (2011) 131:133-40. doi: 10.1038/jid.2010.244

122. Dang W, Xu L, Yin Y, Chen S, Wang W, Hakim MS, et al. IRF-1, RIG-I and MDA5 display potent antiviral activities against norovirus coordinately induced by different types of interferons. Antiviral Res. (2018) 155:4859. doi: 10.1016/j.antiviral.2018.05.004

123. Tretina K, Park ES, Maminska A, MacMicking JD. Interferon-induced guanylate-binding proteins: guardians of host defense in health and disease. J Exp Med. (2019) 216:482-500. doi: 10.1084/jem.20182031

124. Meyer KC, Klatte JE, Dinh HV, Harries MJ, Reithmayer K, Meyer W, et al. Evidence that the bulge region is a site of relative immune privilege in human hair follicles. Br J Dermatol. (2008) 159:107785. doi: 10.1111/j.1365-2133.2008.08818.x

125. Pi LQ, Jin XH, Hwang ST, Lee WS. Effects of calcitonin gene-related peptide on the immune privilege of human hair follicles. Neuropeptides. (2013) 47:51-7. doi: 10.1016/j.npep.2012.07.008

126. Alase AA, El-Sherbiny YM, Vital EM, Tobin DJ, Turner NA, Wittmann M. IFNlambda stimulates MxA production in human dermal fibroblasts via a MAPK-dependent STAT1-independent mechanism. J Invest Dermatol. (2015) 135:2935-43. doi: 10.1038/jid.2015.317

127. Nyberg F, Fransson J, Stephansson E. Proliferation and effects of UVA irradiation in cultured fibroblasts from lesions in cutaneous lupus erythematosus. Exp Dermatol. (2000) 9:537. doi: 10.1034/j.1600-0625.2000.009001053.x

128. Fabbri P, Amato L, Chiarini C, Moretti S, Massi D. Scarring alopecia in discoid lupus erythematosus: a clinical, histopathologic and immunopathologic study. Lupus. (2004) 13:455-62. doi: 10.1191/0961203304lu1041oa

129. Elman SA, Joyce C, Nyberg F, Furukawa F, Goodfield M, Hasegawa M, et al. Development of classification criteria for discoid lupus erythematosus: results of a Delphi exercise. J Am Acad Dermatol. (2017) 77:2617. doi: 10.1016/j.jaad.2017.02.030

130. Shim WH, Jwa SW, Song M, Kim HS, Ko HC, Kim BS, et al. Dermoscopic approach to a small round to oval hairless patch on the scalp. Ann Dermatol. (2014) 26:214-20. doi: 10.5021/ad.2014.26.2.214

131. Pfannes EK, Hadam S, Doge N, Fimmel S, Blume-Peytavi U, Vogt A. Mini-zone cyanoacrylate skin surface stripping: a new method for non-invasive sampling of scalp material. Exp Dermatol. (2016) 25:5556. doi: 10.1111/exd.13006

132. Vogt A, Pfannes EKB, Fimmel S, Hadam S, Andruck A, Kottner J, et al. Infundibular protein and RNA microarray analyses from affected and clinically non-affected scalp in male androgenetic alopecia patients. Exp Dermatol. (2017) 26:518-21. doi: 10.1111/exd.13326

133. Schwartz JR, Shah R, Krigbaum H, Sacha J, Vogt A, Blume-Peytavi U. New insights on dandruff/seborrhoeic dermatitis: the role of the scalp follicular infundibulum in effective treatment strategies. $\mathrm{Br} J$ Dermatol. (2011) 165(Suppl. 2):18-23. doi: 10.1111/j.1365-2133.2011.10573.x

134. Shalbaf M, Alase AA, Berekmeri A, Md Yusof MY, Pistolic J, Goodfield MJ, et al. Plucked hair follicles from patients with chronic discoid lupus erythematosus show a disease-specific molecular signature. Lupus Sci Med. (2019) 6:e000328. doi: 10.1136/lupus-2019000328

135. Miranda JJ, Taype-Rondan A, Tapia JC, Gastanadui-Gonzalez MG, Roman-Carpio R. Hair follicle characteristics as early marker of type 2 diabetes. Med Hypotheses. (2016) 95:39-44. doi: 10.1016/j.mehy.2016. 08.009

136. Plikus MV, Van Spyk EN, Pham K, Geyfman M, Kumar V, Takahashi JS, et al. The circadian clock in skin: implications for adult stem cells, tissue regeneration, cancer, aging, and immunity. J Biol Rhythms. (2015) 30:163-82. doi: 10.1177/07487304145 63537

137. Ghosh D, Bernstein JA, Khurana Hershey GK, Rothenberg ME, Mersha TB. Leveraging multilayered "Omics" data for atopic dermatitis: a road map to precision medicine. Front Immunol. (2018) 9:2727. doi: 10.3389/fimmu.2018.02727

Conflict of Interest Statement: The authors declare that the research was conducted in the absence of any commercial or financial relationships that could be construed as a potential conflict of interest.

Copyright (C) 2019 Berekméri, Tiganescu, Alase, Vital, Stacey and Wittmann. This is an open-access article distributed under the terms of the Creative Commons Attribution License (CC BY). The use, distribution or reproduction in other forums is permitted, provided the original author(s) and the copyright owner(s) are credited and that the original publication in this journal is cited, in accordance with accepted academic practice. No use, distribution or reproduction is permitted which does not comply with these terms. 